\title{
Fatty acid profiling reveals a trophic link between mangrove leaf litter biofilms and the post-larvae of giant tiger shrimp Penaeus monodon
}

\author{
Warima C. Gatune ${ }^{1,2,3, *}$, Ann Vanreusel ${ }^{1}$, Renison Ruwa ${ }^{2}$, Peter Bossier $^{4}$, \\ Marleen De Troch ${ }^{1}$ \\ ${ }^{1}$ Ghent University, Biology Department, Marine Biology, Campus Sterre, Krijgslaan 281-S8, 9000 Ghent, Belgium \\ ${ }^{2}$ Kenya Marine and Fisheries Research Institute, PO Box 80100, 81651 Mombasa, Kenya \\ ${ }^{3}$ Karatina University, School of Natural Resources and Environmental Studies, PO Box 1957-10101, Karatina, Kenya \\ ${ }^{4}$ Ghent University, Faculty of Bioscience Engineering, Laboratory of Aquaculture and Artemia Reference Centre, Rozier 44, \\ 9000 Ghent, Belgium
}

\begin{abstract}
Shrimp ponds integrated with mangroves intercept leaf litter which may contribute to the bioenergetics of shrimps. Since fatty acids (FAs) determine the nutritive value of shrimp food, we analyzed and compared the FA profiles of post-larvae (PL) of Penaeus monodon fed with decomposing litter of Rhizophora mucronata, the associated biofilm, or a nutritionally optimized compound food. Three nutritionally important stages of decomposition $(1,5$, and $10 \mathrm{wk})$ were tested. FA levels of PL at the start of the experiment were used as controls. As litter decomposed, saturated FAs decreased, whereas monounsaturated FAs (MUFAs) and polyunsaturated FAs (PUFAs) increased. PUFA concentrations were higher in biofilm than in the litter. PL fed with litter and biofilm food had higher MUFAs, arachidonic acid (ARA), and eicosapentaenoic acid (EPA) compared to PL fed with a compound food. However, PL fed with compound food had higher linoleic acid and docosahexaenoic acid (DHA). PL fed with $5 \mathrm{wk}$ decomposed litter and its biofilm had a high concentration of bacterial odd carbon chain FAs. FAs in shrimp tissue reflected the FA profiles of the food sources in all treatments, with biofilm and compound food showing a better match. We conclude that (1) mangrove biofilm is a potential source of essential FAs to PL, especially providing ARA, EPA, and DHA; (2) biofilm on mangrove leaf litter may upgrade the nutritional value of PL for their consumers, including humans; and (3) efforts should be made to promote periphytic biofilms in integrated mangrove-shrimp culture practices.
\end{abstract}

*Corresponding author: kgatune@yahoo.com

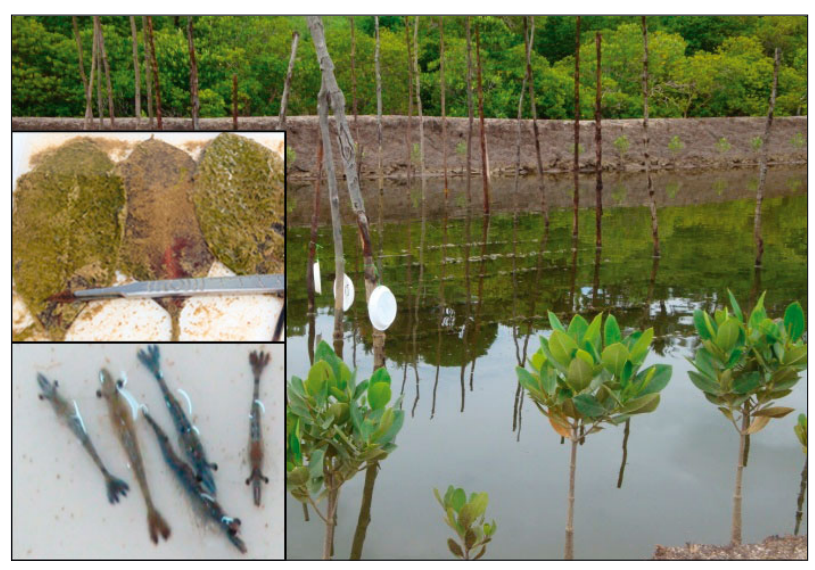

Integrated mangrove-shrimp culture farm at Mtwapa Creek, Kenya. Insets: Biofilm on decomposing mangrove leaf litter of Rhizophora mucronata, and post-larvae shrimp of Penaeus monodon.

Photos: C. Gatune

KEY WORDS: Biofilm $\cdot$ Fatty acid $\cdot$ Shrimp $\cdot$ Silvoculture $\cdot$ Kenya

\section{INTRODUCTION}

Ecological shrimp aquaculture in mangrove systems has gained environmental support because of its tendency to conserve the mangrove forest (Primavera 1998, Fitzgerald 2000). Silvo-culture is a major

(C) The authors 2014. Open Access under Creative Commons by Attribution Licence. Use, distribution and reproduction are unrestricted. Authors and original publication must be credited. 
ecological aquaculture practice in mangrove forests and involves rearing of fish or shrimp in the presence of mangrove trees (Primavera 1998). This integrated approach implies that the shrimp ponds constantly intercept mangrove litter fall which then decomposes under the influence of the micro-biota in the water (Benner \& Hodson 1985, Rajendran \& Kathiresan 2007). Consequently, mangrove leaf litter has a potential role in the food web of the shrimp ponds. A good practice for integrating shrimp culture in mangrove ecosystems should therefore include understanding the role of leaf litter in influencing the allochthonous and autochthonous organic inputs as sources of dietary carbon for shrimp (Burford et al. 2004). Following leaf litter fall, the senescent mangrove leaves start to decompose through a considerable modification by bacteria and fungi and are utilized by epifauna ranging from direct shredders to primary and secondary consumers (Wilson 2002). During this process, a combination of bacteria, microalgae, epifauna, and attracted organic matter form a so-called biofilm (Thompson et al. 2002). As the biofilm includes a wide variety of microflora and -fauna, it may influence the supply of natural food to primary and secondary consumers such as post-larval shrimp (Azim \& Wahab 2005, Abreu et al. 2007).

The availability of nutrients from the decomposing mangrove leaf litter to the shrimp pond food web may vary. For instance, the palatability of the leaf litter may depend on the accumulated microbial nitrogen (Tremblay \& Benner 2006), the concentration of tannins, which is a feeding deterrent (Hall et al. 2006), and the availability of fatty acids (FAs; Mfilinge et al. 2003, 2005). Unsaturated fatty acids, especially the highly unsaturated FAs (HUFAs) which include eicosapentaenoic acid (EPA; 20:5 13 ) and docosahexaenoic acid (DHA; 22:6ஸ3), are essential for the growth of post-larval shrimp (Kanazawa et al. 1977, Lavens \& Sorgeloos 2000, Wouters et al. 2001). These FAs are termed essential, as many organisms, including shrimps, have been found to lack the ability to biosynthesize them and must therefore obtain FAs from their food (Wouters et al. 2001). Read (1981) indicated that juvenile Penaeus indicus have a limited capacity to chain elongate and desaturate polyunsaturated FAs (PUFAs) to HUFAs. Therefore an exogenous source of HUFAs is necessary as part of the essential FAs (EFAs). The $\omega-6$ FAs, such as linoleic $(18: 2 \omega 6)$ and

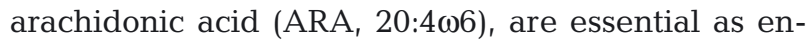
ergy sources, while $\omega-3 \mathrm{FAs}$, such as linolenic acid (18:3 $\omega 3)$ and HUFAs, are utilized for the biosynthesis of longer-chain PUFAs in tissue incorporation (Sandifer \& Joseph 1976). During the decomposition of mangrove leaf litter, FAs are changed either in terms of abundance (Mfilinge et al. 2005) or biochemical state, which could lead to increases in unsaturated FAs and bacterial FAs (Mfilinge et al. 2003). Although shrimp have often been observed to rework mangrove detrital material (Primavera 1996) and use flocculant organic material, such as bioflocs (Crab et al. 2010), the use of mangrove-derived biofilms has been underestimated and understudied to date.

The periphytic biofilm developing on decomposing mangrove leaf litter may change the nutritional quality of decomposing mangrove leaf litter to post-larval penaeid shrimp. Detailed knowledge on the contribution of the biofilm to the transfer of energy from mangrove detritus to shrimp is still fragmented, yet pivotal for the integration of shrimp culture into the mangrove ecosystems. Biomarkers such as FAs are tools (Parrish et al. 2000) that can elucidate the nutritional importance of decomposing mangrove leaf litter and biofilm to post-larval shrimp. FAs are effective trophic markers and can selectively identify potential natural food sources for penaeid shrimp (Parrish et al. 2000, Alfaro et al. 2006).

Here we assessed whether decomposing mangrove leaf litter and the associated biofilm are important food sources to post-larval shrimp. In this assessment, we compared the FA profiles of the shrimp tissue to those of food derived from the decomposing mangrove leaf litter, the associated biofilm, and a nutritionally optimized commercial food for postlarval shrimp. The endpoints were evaluated using similarity in shrimp tissue FAs and the food in the treatments.

\section{MATERIALS AND METHODS}

\section{Study site and standard test organism}

The study was carried out in a mangrove forest and shrimp ponds at the mangrove conservation farm (Majaoni Silvofishery) located on Mtwapa creek along the north coast of Kenya ( $3^{\circ} 57^{\prime} \mathrm{S}, 39^{\circ} 42^{\prime} \mathrm{E}$ ). This site was used to incubate mangrove litter in ponds of 75 to $100 \mathrm{~cm}$ water depth during the SE monsoon (McClanahan 1988). Mtwapa creek is characterized by a reforested mangrove forest dominated by Rhizophora mucronata. Post-larvae of the penaeid shrimp Penaeus indicus and $P$. monodon are commonly fished and cultured within this creek.

Shrimp post-larvae (PL), aged between 15 and $25 \mathrm{~d}$ from the time of hatching (PL 15-25) and originating from the same brooder (cohort) were obtained from 
the Alphakrust shrimp hatchery at Mafia Island, Tanzania (www.alphaafrica.com). They were transported in plastic bags with a pure oxygen headspace for not more than $6 \mathrm{~h}$. On arrival, the PL transport water recorded an average temperature of $27^{\circ} \mathrm{C}$, which was slightly higher than the source packaging temperature of $26.5^{\circ} \mathrm{C}$. PL were acclimatized to laboratory conditions, in a culture tank, for 1 wk before the start of the experiment. The acclimatization conditions were as follows: temperature $28^{\circ} \mathrm{C}_{i}$ aeration $24 \mathrm{~h}$; dissolved oxygen 4-6 $\mathrm{mg} \mathrm{l}^{-1}$; $\mathrm{pH}$ 7-8.5; salinity 28-30. During the acclimatization period, PL were fed with a nutritionally optimized compound food imported from India (Higashimaru zoea to PL 20 feed; crude protein over $52 \%$, see www.aquafeed. com/documents/1254938830_1.pdf, accessed on 15 August 2013).

\section{Litter incubation, biofilm biomass, and feed preparation}

Senescent mangrove leaves (hereafter referred to as mangrove leaf litter), which had just turned yellow-brown and dropped from the trees, were dried in the shade to a constant weight and incubated in sea water, hanging on ropes, in 3 shrimp ponds (representing 3 replicates) for a maximum period of $10 \mathrm{wk}$ (see below). The ponds were not stocked with shrimps. Details concerning other organisms which were associated with the litter incubated in the pond are provided in a companion study (Gatune et al. 2014).

The incubated leaf litter and the attached biofilms were removed at different periods of decomposition $(1,5,10 \mathrm{wk})$. Separate biofilm (B) was obtained from decomposed leaf litter by carefully scraping the periphyton layer. A parallel batch of leaf litter was not scraped to provide food derived from litter with attached biofilm (BL). The leaf litter with attached biofilm and the separate biofilm were then dried at $70^{\circ} \mathrm{C}$ for $48 \mathrm{~h}$ and ground into fine powder. The powder was then mixed with $1 \%$ cellulose binder and $3 \%$ attractant premix (Chen 1993). The mixture was moistened and extruded into 0.01 to $1 \mathrm{~mm}$ pellets. This size is comparable to the size of the mouth of PL 15-25 (Bailey-Brock \& Moss 1992). Detritus of similar size has been found in the gut contents of PL (Bombeo-Tuburan et al. 1993). Processed and pelleted food made of litter with attached biofilm (BL) and separate biofilm (B) was stored frozen at a temperature of $-18^{\circ} \mathrm{C}$ until the time of feeding in the experimental treatments.

\section{Shrimp feeding experiment: set up and design}

Once acclimatized to laboratory conditions, PL were then starved for $24 \mathrm{~h}$ before the start of the experiment. This stage served to provide control values for fatty acid (FA) concentrations at time zero (S0). After this stage, PL were stocked into $70 \mathrm{l}$ circular laboratory tanks receiving 6 food treatments in triplicates as follows: (1) 1, 5, and $10 \mathrm{wk}$ decomposed mangrove leaf litter with attached biofilm (BL1, BL5, BL10); (2) 5 and 10 wk developed biofilm (B5, B10); and (3) compound feed $(\mathrm{CP})$ which acted as a standard. FA profiles of tissues extracted from the tail region of PL shrimp from these treatments were analyzed and referred to as SBL1, SBL5, SBL10, SB5, SB10, and SCP, respectively. These timelines were selected because of the biotic and nutrient characteristics of the decomposing mangrove leaf litter. For instance, after 1 wk of decomposition, microbiota abundance and levels of unsaturated FAs are low (Mfilinge et al. 2003, Gatune et al. 2012); in the fifth week, the litter has high microbiota abundance and high levels of unsaturated FAs (Alikunhi et al. 2010, Gatune et al. 2012), and beyond the tenth week, the litter is characterized by a high (>90\%) loss of tannins (Rajendran \& Kathiresan 2000). FA composition of the tail tissue of $P$. monodon PL from the different treatments was compared to the FA composition of the food.

The shrimp feeding experiment was carried out for a period of $16 \mathrm{~d}$. PL starved for $24 \mathrm{~h}$ were stocked into the $70 \mathrm{l}$ experiment culture tanks in triplicate at a density of $2 \mathrm{PL}^{-1}$. The culture water was obtained from a reservoir tank and treated by filtration through a sand filter, then through a cartilage filter and disinfected with UV. The culture water was replenished by adjusting the flow-through system to achieve a water exchange rate of $50 \% \mathrm{~d}^{-1}$. Dissolved oxygen was maintained by continuously aerating water in both reservoir and experimental tanks through airstones. Feeding with leaf litter-derived food was adjusted to ensure maintaining a leaf litter density not exceeding $0.5 \mathrm{~g} \mathrm{l}^{-1}$ (Hai \& Yakupitiyage 2005). A feeding rate of $10 \%$ dry body weight was maintained for all food types. To estimate the dry weight, prior to the feeding experiment, 10 PL were sampled at random and dried in an oven at $70^{\circ} \mathrm{C}$ for $48 \mathrm{~h}$ and subsequently weighed. This dry weight was translated into the total PL stocked in the experimental tanks and was used to calculate the daily proportion of the dry food. Food items were offered twice a day (morning and afternoon) and doubled every $3.5 \mathrm{~d}$. Remnant food and fecal pellets were removed every day in the morning before feeding. 


\section{FA extraction and analysis}

Samples of tail tissue (intestine removed) and pelleted food were stored at $-80^{\circ} \mathrm{C}$. Prior to the FA extraction, the frozen samples were freeze-dried (lyophilized) and weighed into triplicate samples of $50 \mathrm{mg}$ using a balance (Mettler Toledo, AX 205). FAs were extracted and methylated to FA methyl esters (FAMEs) by a modified 1-step derivatization method following Abdulkadir \& Tsuchiya (2008); see also De Troch et al. (2012). The FA methylnonadecanoate C19:0 was added as an internal standard for later quantification (Fluka 74208). The boron trifluoridemethanol reagent was replaced by a $2.5 \% \mathrm{H}_{2} \mathrm{SO}_{4}$ methanol solution since $\mathrm{BF}_{3}$-methanol can cause artefacts or loss of PUFAs. Hexane was dried from FAMEs using a Rapid Vap (Labconco) at a vortex speed of $50 \%, 30^{\circ} \mathrm{C}, 240$ mbar, and then dissolved into $1 \mathrm{ml}$ hexane and analyzed using a Hewlett Packard 6890N GC equipped with a mass spectrometer (HP 5973). The samples were run in splitless mode injecting $1 \mu \mathrm{l}$ extract per run at an injector temperature of $250^{\circ} \mathrm{C}$ using an HP88 column $(60 \mathrm{~m} \times 0.25 \mathrm{~mm}$ internal diameter $\times 0.20 \mu \mathrm{m}$ film thickness; Agilent $\mathrm{J} \& W)$. Helium was used as the carrier gas. The oven temperature was programmed at $50^{\circ} \mathrm{C}$ for 2 min, followed by a ramp at $25^{\circ} \mathrm{C} \min ^{-1}$ to $175^{\circ} \mathrm{C}$ and then a final ramp at $2^{\circ} \mathrm{C} \min ^{-1}$ to $230^{\circ} \mathrm{C}$ with a $4 \mathrm{~min}$ hold. The FAMEs were identified by comparison with the retention times and mass spectra of authentic standards and available spectra in mass spectral libraries (WILEY), and analyzed with the software MSD ChemStation (Agilent Technologies). Quantification of individual FAMEs was accomplished by the use of external standards (Supelco no. 47885, Sigma-Aldrich).

\section{Water quality parameters and data analysis}

Water quality in the experimental units was recorded weekly by measuring temperature, dissolved oxygen, $\mathrm{pH}$, salinity, and total ammonium nitrogen.

Statistical analyses (ANOVA) were conducted with STATISTICA 7.0 software. Prior to the parametric ANOVAs, all data were checked for normality and variance homogeneity requirements using Levene's test. Data which did not meet normality requirements after being transformed were analyzed non-parametrically with Kruskal-Wallis and median tests. Multidimensional scaling and analysis of similarity (ANOSIM) were used to compare similarity (BrayCurtis) in FA composition using Primer 6.0 software (Clarke \& Gorley 2006).

\section{RESULTS}

\section{FA composition of the feed}

The abundance of 6 specific FAs was relatively high in food derived from decomposing mangrove leaf litter and biofilm (Table 1). Saturated FAs (SAFAs), especially palmitic acid (C16:0), were the most abundant FAs in all food types, whereas C18:0 was most abundant in food derived from leaf litter decomposed for 5 wk (BL5). Monounsaturated FAs (MUFAs) such as 16:1 107 were most abundant in food derived from biofilm separated from leaf litter decomposed for $10 \mathrm{wk}$

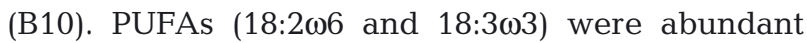
only in food from the least decomposed leaf litter and less developed biofilm (BL1 and B5). Other PUFAs, especially ARA, EPA, and DHA, were abundant in food from the more decomposed leaf litter (BL10) and more

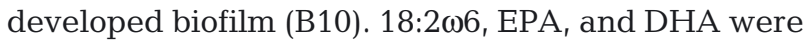
markedly high in the CP food compared to the leaf litter and biofilm-derived food.

\section{FA composition of shrimp tissue}

PL fed with decomposing leaf litter food (SBL) were found to have a low total FA concentration and lower levels of PUFA compared to PL fed with biofilm (SB) and $\mathrm{CP}$ food. However, they had relatively higher levels of MUFAs than PL fed with CP food (Fig. 1). The concentration of HUFAs in PL fed with leaf litter food (SBL) increased between Weeks 1 and 10, as it also did in the food source. CP food recorded the highest $\omega 3: \omega 6$ ratio. However, when comparing the $\omega 3: \omega 6$ ratio of $\mathrm{PL}$ tissue to that of their food, $\mathrm{PL}$ fed CP food had a lower ratio compared to PL fed biofilm and litter food. PL fed 5 wk biofilm (B5) had the highest ratio (Table 1). PL fed with $\mathrm{CP}$ food had significantly higher levels of DHA $\left(7.8 \pm 0.2 \mathrm{mg} \mathrm{g}^{-1}\right)$ than PL fed with leaf litter $\left(3.6 \pm 0.8 \mathrm{mg} \mathrm{g}^{-1}\right)$ and biofilm food $\left(5.6 \pm 1.3 \mathrm{mg} \mathrm{g}^{-1}\right.$; ANOVA, $\left.F_{6,14}=10.1 ; \mathrm{p}<0.05\right)$. PL fed with 5 and 10 wk old biofilm had higher mean levels of DHA $\left(5.2 \pm 1.3\right.$ and $\left.6.0 \pm 1.2 \mathrm{mg} \mathrm{g}^{-1}\right)$ than PL fed with leaf litter food of the same age $(3.8 \pm 0.8$ and $4.0 \pm 1.1 \mathrm{mg} \mathrm{g}^{-1}$ ). EPA was abundant in PL fed with leaf litter and biofilm food, while it was significantly lower in PL fed with CP food (Tukey post hoc; $\mathrm{p}=$ 0.04). For $\omega-6$ FAs, ARA was significantly higher in PL fed with leaf litter and biofilm food compared to PL fed with CP food, whereas 18:2 16 was significantly higher in PL fed with CP food (ANOVA, $F_{6,14}=$ 5.58; $\mathrm{p}<0.05)$. Odd carbon chain FAs, viz. C15:0 and C17:0 FAs (Fig. 2), were abundant in PL fed with bio- 


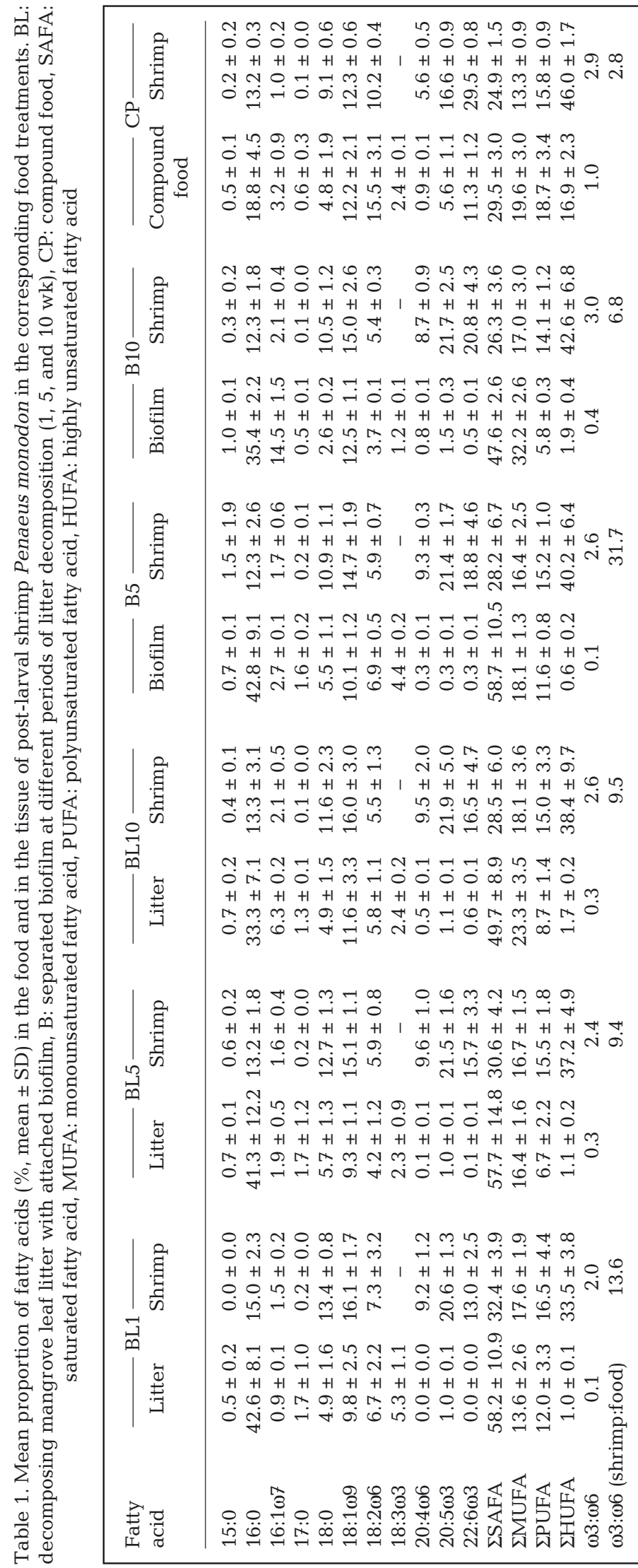

film developed for $5 \mathrm{wk}$. As these FA concentrations were characterized by very high within-group variances, no statistical difference between the different treatments was found (Kruskal-Wallis test, $\left.H_{6,21}=13.43 ; \mathrm{p}>0.05\right)$.

The results of multivariate analysis showed that FAs of the PL from the treatments were significantly different (1-way ANOSIM; Global R $=0.523$;

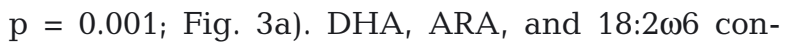
tributed most to the dissimilarity between the control shrimp (S0) and PL fed with different food types (SIMPER; SCP: DHA 30.7\%; SBL: ARA 33.0\%; SB: $18: 2 \omega 635.8 \%$ ). In terms of FA composition, PL fed with CP food were more similar in FA composition to the PL fed with biofilm than to PL fed with decomposed leaf litter food (SIMPER: $88.1 \%$ and $68.5 \%$, respectively). DHA contributed most to the high similarity between PL fed with CP and PL fed with biofilm food than PL fed with leaf litter food and control (SIMPER: 69.4\%, 56.2\%, and 69.3\%, respectively).

When comparing the consumers to their food, PL fed with $\mathrm{CP}$ food were most similar to their food source (SIMPER: 78.4\%), followed by PL fed with litter (SIMPER: 18.9\%) and PL fed with biofilm food $(13.3 \%$; Fig. 3b). Among the specific FA groups, SAFAs contributed most to the high similarity between PL and their leaf litter and biofilm-derived food (SIMPER: 91.2\%). For example, C16:0 (SIMPER: $94.3 \%$ ) was high in PL tissue vis-à-vis leaf litter and biofilm-derived food sources. PUFAs contributed to the high similarity between PL and their $\mathrm{CP}$ food (SIMPER: 82.3\%), as DHA (SIMPER: $93.0 \%$ ) was high in both.

\section{DISCUSSION}

\section{FA composition and dynamics in food sources}

SAFAs, especially C16:0, were observed to de-

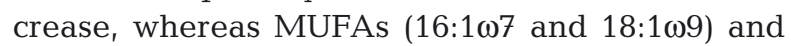

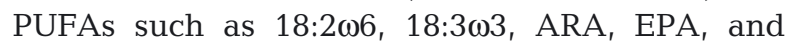
DHA increased as mangrove leaf litter progressively decomposed and the periphytic biofilm developed (Table 1). Similar observations were made in a previous study (Mfilinge et al. 2003), where during decomposition, FA composition in mangrove leaf litter changed from predominantly SAFAs to MUFAs and PUFAs. Unlike unsaturated FAs such as MUFAs and PUFAs, which are essential to penaeid shrimps (Kanazawa et al. 1977, D'Abramo 1989), SAFAs are not essential since 

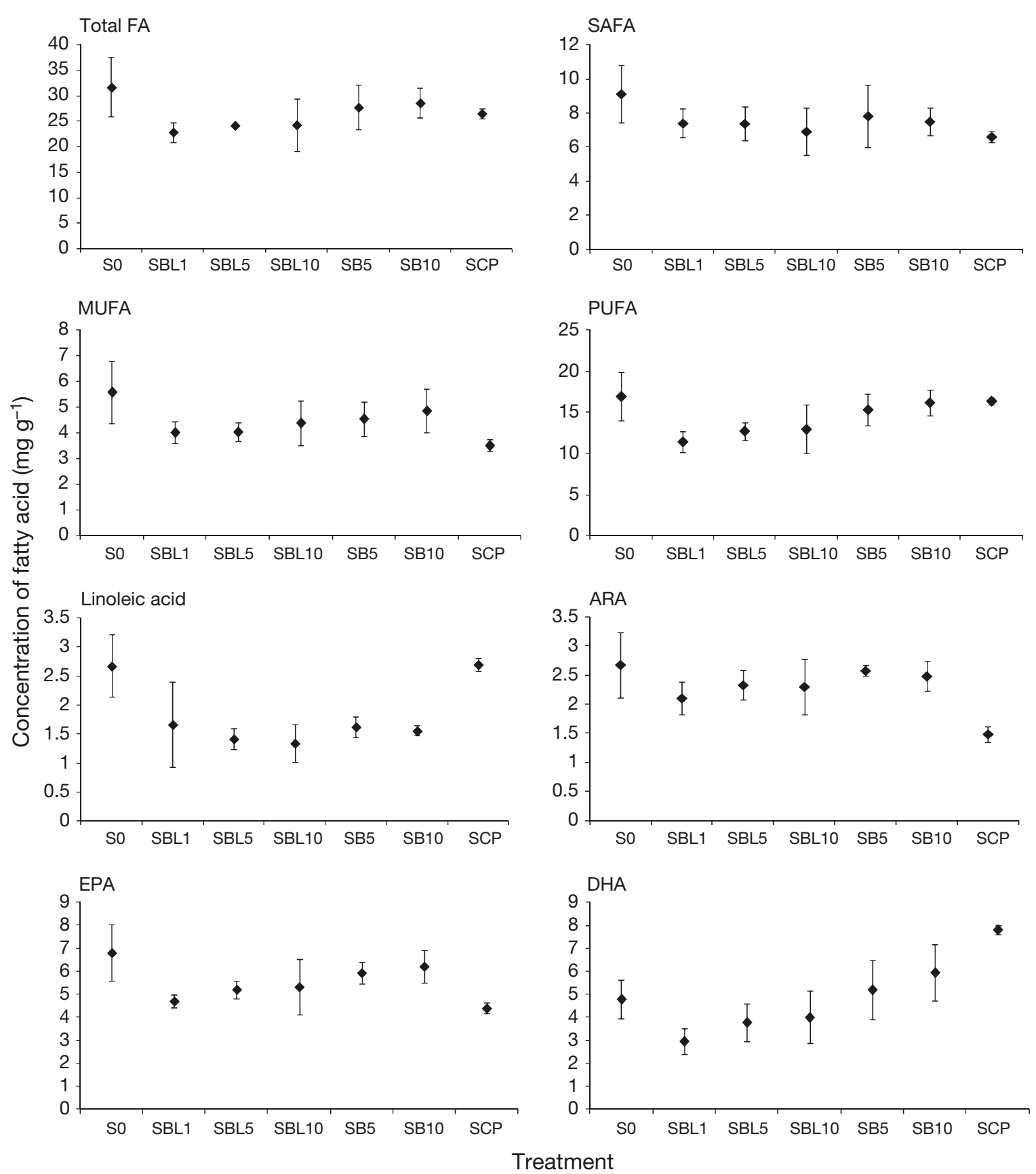

Fig. 1. Fatty acid (FA) groups and essential FAs in tissue of post-larval shrimp Penaeus monodon fed with different food types. SBL: shrimp fed with decomposing mangrove leaf litter with attached biofilm, SB: shrimp fed with separated biofilm at different periods of litter decomposition (1,5, and $10 \mathrm{wk})$, S0: start of experiment, SCP: compound food, SAFA: saturated FA, MUFA: monounsaturated FA, PUFA: polyunsaturated FA, ARA: arachidonic acid, EPA: eicosapentaenoic acid, DHA: docosa-hexaenoic acid

they can be bio-synthesized in the tissue. According to D'Abramo (1989), shrimp and other animals possess a delta 9-desaturase enzyme system which can convert SAFAs to MUFAs. This observation suggests the important role that the process of litter decomposition and biofilm development may play in improv- ing the health of PL shrimp in ecological shrimp culture ecosystems. However, caution should be taken, since a unique aspect of lipid nutrition in crustaceans is that cholesterol is required. For instance, a level of $0.5 \%$ cholesterol is recommended in the diet of Penaeus monodon juveniles (Shiau 1998). Decompo- 


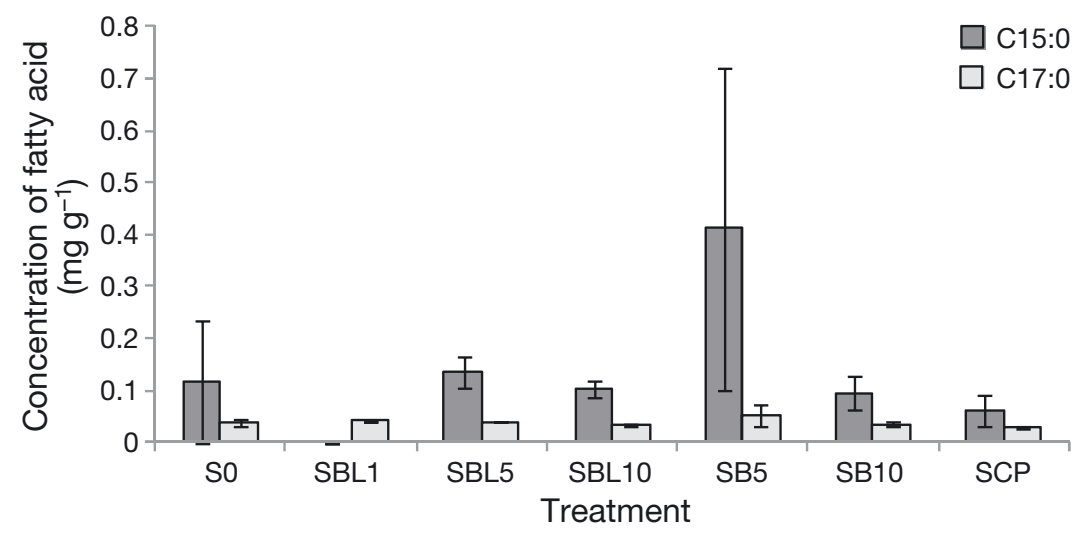

Fig. 2. Odd carbon chain fatty acids (FAs) in tissue of post-larval shrimp Penaeus monodon fed with different food types. Treatment groups as in Fig. 1 loos 2000), they are therefore the best suited FA category to highlight the ecological importance of the decomposing mangrove leaf litter. The mobilization of EFAs in the biofilm developing on the decomposing leaf litter can contribute to the indirect energy transfer from decomposing mangrove leaf litter to higher trophic levels in wider mangrove estuarine and shrimp culture ecosystems. The contribution of EFAs from decomposing mangrove leaf litter to mangrove estuarine and integrated shrimp culture ecosystems may be largely limited by the reduced palatability of the mangrove leaf litter caused by the presence of tannins which may deter grazers (Scalbert 1991). However, the growth of the periphytic biofilm can buffer or rather condition the effect of such chemical deterrents by mobilizing the counteractive positive effects of EFAs to the physiology of consumers (Sandifer \& Joseph 1976, Lavens \& Sorgeloos 2000). EFAs are found in the micro-algae and epifauna (Parrish 2009), which are among the major constituents of the periphytic biofilm (Gatune et al. 2012, 2014). Micro-algae such as diatoms and epifauna such as copepods and polychaetes are typically rich in EPA and DHA (Parrish et al. 2000, 2012). Polychaetes are important food for penaeid shrimps (Nunes \& Parsons 2000). The ecological importance of mangrove leaf litter to PL shrimp can therefore be linked to the progress of decomposition and growth of the associated biofilm. essential for the growth of penaeid shrimp (Kanazawa et al. 1979, D'Abramo 1989, Lavens \& Sorge-

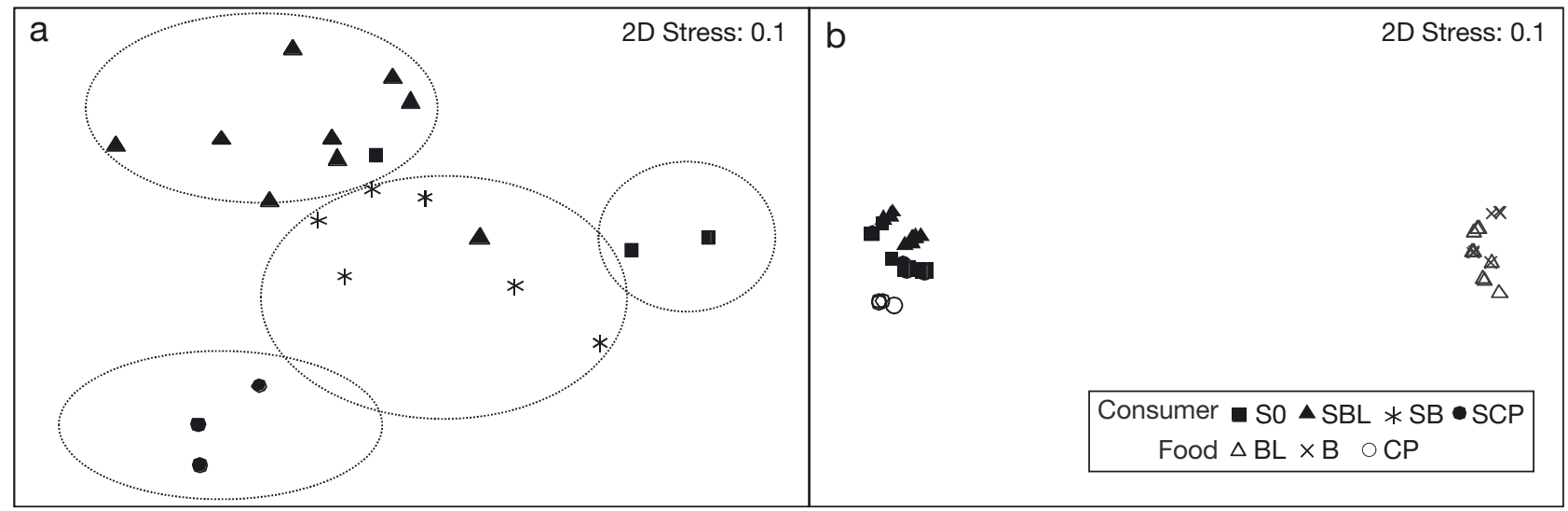

Fig. 3. Multidimensional scale plot based on Bray-Curtis similarity between absolute fatty acid (FA) composition of post-larval shrimp Penaeus monodon tissue and food treatments. S0: start of experiment, SBL: shrimp fed with litter and attached biofilm, SB: shrimp fed with biofilm, SCP: shrimp fed with compound food, BL: litter and attached biofilm food, B: biofilm food, CP: compound food. Figures represent comparison of FAs between (a) consumers and (b) consumers and food 


\section{FA composition and dynamics in shrimp tissuew}

The high abundance of total FAs in the tissue of shrimp fed with biofilm food compared to those fed with mangrove leaf litter food (Fig. 1) suggests the importance of biofilm in enhancing the nutritive value of decomposing mangrove leaf litter. Biofilms developing on decomposing mangrove litter contain bacteria, micro-algae, and epifauna of nutritional value to PL shrimp (Gatune et al. 2012, 2014). Biofloc, which is similar to biofilm, contains higher total $\omega-6$ FA content in the presence of glycerol carbon (Crab et al. 2010). This could imply possible mobilization of FA valuable carbon sources in biofilm. Lipids play a major role in the physiological performance of shrimp by providing energy and enhancing growth and reproduction (Sandifer \& Joseph 1976, Lavens \& Sorgeloos 2000). In addition, our SIMPER results showed that DHA contributed most to the close resemblance between the shrimps fed with compound food and those fed with biofilm food. Furthermore, DHA was markedly abundant in shrimp fed with compound food. Compound food is specifically formulated to optimize the abundance of EFAs which are essential for the growth of PL shrimp, whereby DHA is the dominating EFA in the DHA/EPA/ARA ratio (Lavens \& Sorgeloos 2000). The dominating nature of DHA in shrimp fed with biofilm in combination with the fact that other EFAs such as EPA and ARA were higher in shrimp fed with biofilm compared to those fed with leaf litter highlights the potential ecological function of biofilm in nourishing PL shrimp in a mangrove ecosystem. DHA supports important physiological functions in penaeid shrimps such as reproduction, growth, metamorphosis from larvae to juveniles, survival, and resilience to stressful conditions (Read 1981, Bell et al. 1984, Lavens \& Sorgeloos 2000). Lavens \& Sorgeloos (2000) documented in their review that feeding EPA- and DHAenriched Artemia to $P$. monodon PL resulted in improved PL quality by increasing their ability to survive exposure to salinity shocks. When shrimps are migrating to estuaries, they are exposed to a wide variation in salinities that influence metamorphosis of their osmoregulatory capacities (Palacios \& Racotta 2007). Due to their stagnant water regime and tidal-dependent water exchange, shrimp culture ponds integrated in a mangrove system experience large fluctuations of salinity among other physicochemical stressors, making shrimp stocks vulnerable to diseases (Tendencia \& Verreth 2011). The development of biofilm on decomposing mangrove leaf litter, intercepted in shrimp ponds and mangrove estuaries, is therefore an important precedence in building the resilience capacity of PL shrimp to the variable physicochemical conditions characterizing these habitats.

Shrimp fed with 5 wk decomposed mangrove leaf litter and biofilm food recorded higher levels of odd carbon chain FAs (C15:0 and C17:0), which are important FA biomarkers for bacteria (Ederington et al. 1995, Alikunhi et al. 2010). Although these FAs in food sources did not show a clearly matching trend in both the odd carbon chain FAs, and were highly variable, the higher mean values of C15:0 closely coincide with our previous study where the highest bacterial abundance was observed in mangrove leaf litter decomposed for a period of 3 to $4 \mathrm{wk}$ (Gatune et al. 2012). Bacteria have been suggested as an important nutrition source for PL shrimp in promoting grazing ability, growth, and survival when occurring as periphyton on structures in semi-intensive and extensive ponds (Bratvold \& Browdy 2001, Azim \& Wahab 2005, Keshavanath \& Gangadhar 2005) and should therefore be considered in biofilm studies related to the generation and transfer of energy in a mangrove estuarine ecosystem.

Ecological shrimp culture implies a strong reliance on natural food supply, and its success is determined by the abundance of preferred nutrients, including EFAs (Kanazawa et al. 1979, Rothlisberg 1998). In our study, conclusions on the contribution of decomposing mangrove leaf litter and its associated biofilm to the bioenergetics of PL shrimp are also based on comparative relationships of the FA composition of the shrimp tissue to that of their food sources. Their biological specificity, and the fact that they are in most cases transferred from primary producers to higher trophic levels, makes FAs suitable for use as biomarkers (Parrish et al. 2000). Shrimp fed with

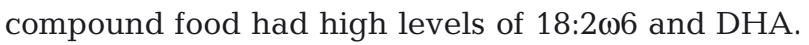
These 2 FAs were also high in the compound food. A progressively higher level of DHA was observed in shrimp in tandem with increasing levels of DHA in their leaf litter and biofilm food sources. The observations of similarity in FA composition of shrimp tissue to that of their food seem to relate to the intertrophic conservative nature of the FAs (Parrish et al. 2000). It also adds confidence to the nutritive importance of decomposing mangrove leaf litter and its associated biofilm to PL shrimp. The distinctive resemblance of tissue FAs of PL shrimp to those of their food and the fact that shrimps fed with compound and biofilm food showed a better match gives a strong basis for drawing our conclusion on supporting the nutritive potential of biofilm. 
The importance of biofilm is finally demonstrated by the fact that PL fed biofilm tend to upgrade the nutritional quality of their food more efficiently compared to those fed CP (Table 1). Despite the higher $\omega 3: \omega 6$ ratio of CP food and therefore its higher nutritional quality, shrimp fed biofilm and litter food tended to have a higher $\omega 3: \omega 6$ ratio than what could be expected based on the ratio of their food. This is especially true for the treatment with biofilm (Table 1). This observation suggests that shrimp feeding on biofilm can develop special bioconversion in elevating the tissue $\omega 3: \omega 6$ ratio. This ability could be linked to a potential pro-nutritional quality of the biofilm and can be used to improve the nutritional value of shrimp for their consumers, including humans.

\section{CONCLUSION}

Our study illustrated that biofilm is a potential source of EFAs to PL shrimp, especially ARA, EPA, and DHA, and that biofilm on mangrove leaves may provide PL with the bioconversion ability to upgrade their nutritional value for their consumers, including humans, more so during the fifth week of litter decomposition. In terms of the fate of FAs as biomarkers, FAs of the food were found to be reflected in the consumers' FA profiles, but this depended on the food source, with biofilm and compound food showing a better match. The study therefore strongly suggests that biofilm is a potential source of nutritive food to PL shrimp foraging on decomposing mangrove leaf litter in an integrated mangrove-shrimp culture ecosystem, and efforts should be made to promote it. This study highlights the opportunity that mangroves provide for ecological fish/shrimp culture practices, specifically where ponds are sited in open areas bordering a mangrove forest or mangrove seedlings are planted along the inner side of the pond dykes. Furthermore, our results thus promote mangrove reforestation of bare grounds. Although this study only tested for the effect of leaf litter from Rhizophora mucronata, we can expect that different mangrove species may vary in their biochemical impact. The use of FAs as biomarkers may further reveal the contribution of these mangrove species as well and allow us to formulate more general statements on the practice of ecological shrimp farming.

Acknowledgements. W.C.G. thanks the Flemish InterUniversity Council (VLIR) for financial support to follow an international $\mathrm{PhD}$ program in Biology at Ghent University, Belgium, and an additional short research stay (SRS) schol- arship to prepare this manuscript for publication. M.D.T. is a postdoctoral fellow financed by the Special Research Fund of Ghent University (GOA project 01GA1911W). We thank Glen F. Bieber based at Mbengani Fisheries Development Centre in Bagamoyo, Tanzania, for facilitating export and donating the test post-larvae shrimp. Dirk Van Gansbeke (Ghent University, Marine Biology) assisted in the analysis of the fatty acids. We also thank KMFRI laboratory technicians Eric Magara, Omondo, Mwendwa Mbaluka, Boaz, and the youth and community members of the Majaoni silvofishery project, Kenya, for their field assistance. Three anonymous referees provided constructive remarks that helped improve the manuscript.

\section{LITERATURE CITED}

Abdulkadir S, Tsuchiya M (2008) One-step method for quantitative and qualitative analysis of fatty acids in marine animal samples. J Exp Mar Biol Ecol 354:1-8

Abreu PC, Ballester ELC, Odebrecht C, Wasielesky W, Cavalli RO, Graneli W, Anesio AM (2007) Importance of biofilm as food source for shrimp (Farfantepenaeus paulensis) evaluated by stable isotopes $\left(\delta^{13} \mathrm{C}\right.$ and $\left.\delta^{15} \mathrm{~N}\right)$. J Exp Mar Biol Ecol 347:88-96

Alfaro AC, Thomas FO, Sergent L, Duxbury M (2006) Identification of trophic interactions within an estuarine food web (northern New Zealand) using fatty acid biomarkers and stable isotopes. Estuar Coast Shelf Sci 70:271-286

Alikunhi NM, Narayanasamy R, Kandasamy K (2010) Fatty acids in an estuarine mangrove ecosystem. Rev Biol Trop 58:577-587

Azim ME, Wahab MA (2005) Periphyton based pond polyculture In: Azim ME, Verdegem MCJ, van Dam AA, Beveridge MCM (eds) Periphyton: ecology, exploitation and management. CABI Publishing, Wallingford, p 207-222

Bailey-Brock JH, Moss SM (1992) Penaeid taxonomy, biology and zoogeography. In: Fast AW, Lester LJ (eds) Marine shrimp culture: principles and practices. Developments in aquaculture and fisheries science. Elsevier Science, Amsterdam, p 9-27

Bell JD, Pollard DA, Burchmore JJ, Pease BC, Middleton MJ (1984) Structure of a fish community in a temperate tidal mangrove creek in Botany Bay, New South Wales. Aust J Mar Freshw Res 35:33-46

Benner R, Hodson RE (1985) Microbial degradation of the leachable and lignocellulosic components of leaves and wood from Rhizophora mangle in a tropical mangrove swamp. Mar Ecol Prog Ser 23:221-230

Bombeo-Tuburan I, Guanzon NG Jr, Schroeder GL (1993) Production of Penaeus monodon (Fabricius) using four natural food types in an extensive system. Aquaculture 112:57-65

Bratvold D, Browdy CL (2001) Effects of sand sediment and vertical surfaces (Aquamats) on production, water quality, and microbial ecology in an intensive Litopenaeus vannamei culture system. Aquaculture 195:81-94

> Burford MA, Preston NP, Minh TH, Hoa TT, Bunn SE, Fry VM (2004) Dominant sources of dietary carbon and nitrogen for shrimp reared in intensive rice-shrimp ponds. Aquacult Res 35:194-203

Chen HY (1993) Recent advances in nutrition of Penaeus monodon. J World Aquacult Soc 24:231-240

Clarke KR, Gorley RN (2006) PRIMER v6. In: PRIMER-E (ed) User manual/tutorial. Primer-E, Plymouth 
Crab R, Chielens B, Wille M, Bossier P, Verstraete W (2010) The effect of different carbon sources on the nutritional value of bioflocs, a feed for Macrobrachium rosenbergii postlarvae. Aquacult Res 41:559-567

D'Abramo LR (1989) Lipid requirements in shrimp. Advances in tropical aquaculture, Tahiti, 20 Feb to 4 Mar 1989, AQUACOP. IFREMER Actes Colloq 9:271-285

$>$ De Troch M, Boeckx P, Cnnude C, Van Gansbeke D, Vanreusel A, Vincx M, Caramujo MJ (2012) Bioconversion of fatty acids at the basis of marine food webs: insights from a compound-specific stable isotope analysis. Mar Ecol Prog Ser 465:53-67

Ederington MC, McManus GB, Harvey HR (1995) Trophic transfer of fatty acids, sterols and triterpenoid alcohol between bacteria, a ciliate, and the copepod Acartia tonsa. Limnol Oceanogr 40:860-867

Fitzgerald WJ Jr (2000) Integrated mangrove forest and aquaculture systems in Indonesia. In: Primavera JH, Garcia LMB, Castranos MT, Surtida MB (eds) Mangrovefriendly aquaculture. Southeast Asian Fisheries Development Center (SEAFDEC), Iloilo City, p 21-34

- Gatune C, Vanreusel A, Cnudde C, Ruwa R, Bossier P, De Troch M (2012) Decomposing mangrove litter supports a microbial biofilm with potential nutritive value to penaeid shrimp post larvae. J Exp Mar Biol Ecol 426-427:28-38

Gatune C, Vanreusel A, Ruwa R, Bossier P, De Troch M (2014) Growth and survival of post-larval giant tiger shrimp Penaeus monodon feeding on mangrove leaf litter biofilms. Mar Ecol Prog Ser 511:117-128

Hai TN, Yakupitiyage A (2005) The effects of the decomposition of mangrove leaf litter on water quality, growth and survival of black tiger shrimp (Penaeus monodon Fabricius, 1798). Aquaculture 250:700-712

Hall D, Lee SY, Meziane T (2006) Fatty acids as trophic tracers in an experimental estuarine food chain: tracer transfer. J Exp Mar Biol Ecol 336:42-53

Kanazawa A, Teshima S, Tokiwa S (1977) Nutritional requirements of prawn.VII. Effect of dietary lipids on growth. Bull Jpn Soc Sci Fish 43:849-856

Kanazawa A, Teshima S, Endo M (1979) Requirements of prawn, Penaeus japonicus, for essential fatty acids. Mem Fac Fish Kagoshima Univ 28:27-33

Keshavanath P, Gangadhar B (2005) Research on periphyton-based aquaculture in India. In: Azim ME, Verdegem MCJ, Van Dam AA, Beveridge MCM (eds) Periphyton: ecology, exploitation and management. CABI Publishing, Wallingford, p 223-236

Lavens P, Sorgeloos P (2000) Experiences on importance of diet for shrimp postlarval quality. Aquaculture 191: 169-176

- McClanahan TR (1988) Seasonality in East Africa's coastal waters. Mar Ecol Prog Ser 44:191-199

> Mfilinge PL, Meziane T, Bachok Z, Tsuchiya M (2003) Fatty acids in decomposing mangrove leaves: microbial activity, decay and nutritional quality. Mar Ecol Prog Ser 265: 97-105

Mfilinge PL, Meziane T, Bachok Z, Tsuchiya M (2005) Total lipid and fatty acid classes in decomposing mangrove leaves of Bruguiera gymnorrhiza and Kandelia candel: significance with respect to lipid input. J Oceanogr 61: 613-622

Nunes AJP, Parsons GJ (2000) Effects of the Southern brown shrimp, Penaeus subtilis, predation and artificial feeding on the population dynamics of benthic polychaetes in tropical pond enclosures. Aquaculture 183:125-147
Palacios E, Racotta IS (2007) Salinity stress test and its relation to future performance and different physiological responses in shrimp postlarvae. Aquaculture 268: $123-135$

Parrish CC (2009) Essential fatty acids in aquatic food webs. In: Arts MT, Brett MT, Kainz MJ (eds) Lipids in aquatic ecosystems. Springer, Dordrecht, p 309-326

Parrish CC, Abrajano TA, Budge SM, Helleur RJ, Hudson ED, Pulchan K, Ramos C (2000) Lipid and phenolic biomarkers in marine ecosystems: analysis and applications. In: Wangersky P (ed) The handbook of environmental chemistry. Part D: Marine chemistry. Springer, Berlin, p 193-233

Parrish CC, French VM, Whiticar MJ (2012) Lipid class and fatty acid composition of copepods (Calanus finmarchicus, C. glacialis, Pseudocalanus sp., Tisbe furcata and Nitokra lacustris) fed various combinations of autotrophic and heterotrophic protists. J Plankton Res 34:356-375

Primavera JH (1996) Stable carbon and nitrogen isotope ratios of penaeid juveniles and primary producers in a riverine mangrove in Guimaras, Philippines. Bull Mar Sci 58:675-683

Primavera JH (1998) Tropical shrimp farming and its sustainability. In: De Silva S (ed) Tropical mariculture. Academic Press, New York, NY, p 257-289

Rajendran N, Kathiresan K (2000) Biochemical changes in decomposing leaves of mangroves. Chem Ecol 17: 91-102

Rajendran N, Kathiresan K (2007) Microbial flora associated with submerged mangrove leaf litter in India. Rev Biol Trop 55:393-400

Rajendran N, Matsuda O, Imamura N, Urushigwa Y (1995) Microbial community structure analysis of euxinic sediments using phospholipid fatty acid biomarkers. J Oceanogr 51:21-38

> Read GHL (1981) The response of Penaeus indicus (Crustacea: Penaeidea) to purified and compounded diets of varying fatty acid composition. Aquaculture 24:245-256

Rothlisberg PC (1998) Aspects of penaeid biology and ecology of relevance to aquaculture: a review. Aquaculture 164:49-65

> Sandifer PA, Joseph JD (1976) Growth responses and fatty acid composition of juvenile prawns (Macrobrachium rosenbergii) fed a prepared ration augmented with shrimp head oil. Aquaculture 8:129-138

> Scalbert A (1991) Antimicrobial properties of tannins. Phytochemistry 30:3875-3883

Shiau SY (1998) Nutrient requirements of penaeid shrimps. Aquaculture 164:77-93

Tendencia EA, Verreth JAJ (2011) Temperature fluctuation, low salinity, water microflora: risk factors for WSSV outbreaks in Penaeus monodon. Isr J Aquacult Bamidgeh IIC.63.2011.548

Thompson FL, Abreu PC, Wasielesky W (2002) Importance of biofilm for water quality and nourishment in intensive shrimp culture. Aquaculture 203:263-278

Tremblay L, Benner R (2006) Microbial contributions to Nimmobilization and organic matter preservation in decaying plant detritus. Geochim Cosmochim Acta 70: 133-146

- Wilson JG (2002) Productivity, fisheries and aquaculture in temperate estuaries. Estuar Coast Shelf Sci 55:953-967

> Wouters R, Lavens P, Nieto J, Sorgeloos P (2001) Penaeid shrimp nutrition. An updated review on research and development. Aquaculture 202:1-21 